\title{
High-field (high-frequency) EPR spectroscopy and structural characterization of a novel manganese(III) corrole
}

\author{
Jesper Bendix, ${ }^{a}$ Harry B. Gray, ${ }^{* a}$ Galina Golubkov ${ }^{b}$ and Zeev Gross ${ }^{* b}$ \\ a Beckman Institute, California Institute of Technology, Pasadena, California 91125, USA \\ ${ }^{b}$ Department of Chemistry and Institute of Catalysis Science and Technology, Technion - Israel Institute of \\ Technology, Haifa 32000, Israel.E-mail: chr10zg@tx.technion.ac.il
}

Received (in Cambridge, UK) 2nd August 2000, Accepted 30th August 2000

First published as an Advance Article on the web

The X-ray structure, magnetic susceptibility, and high-field (high-frequency) EPR spectrum of manganese 5,10,15-tris(pentafluorophenyl) corrole unambiguously establish that the complex contains an isolated, slightly rhombic, manganese(III) center.

Manganese(III) porphyrins are very efficient catalysts for functionalization of hydrocarbons in processes that involve high valent intermediates. ${ }^{1,2}$ Spectroscopic identification of odd-spin manganese(IV) and spin-coupled manganese(v) porphyrins by magnetic resonance measurements is relatively straightforward, via utilization of EPR and NMR, respectively. ${ }^{3-6}$ However, even-spin manganese(III) porphyrins are EPR-silent (X-band) and their NMR spectra are not easily interpretable. For example, an early assignment of the origin of the paramagnetic shifts in manganese(III) porphyrins was recently revised, ${ }^{7}$ and there is some evidence indicating that the complexes might better be described as manganese(II) porphyrin radical cations. ${ }^{8}$ A recent development relevant to this question is the utilization of highfield (high-frequency) EPR (HF-EPR) spectroscopy for elucidation of the electronic structures of high-spin manganese(III) complexes. ${ }^{9}$

The close relationship of porphyrins and corroles suggests that metallocorroles could also be very interesting catalysts. This proposal was only recently explored, taking advantage of the novel electron-poor 5,10,15-tris(pentafluorophenyl)corrole, $\mathrm{H}_{3} \mathrm{tpfc},{ }^{10}$ whose substitution pattern matches that of the most active porphyrin-based catalysts. First, it was demonstrated that the iron and rhodium complexes of $\mathrm{H}_{3}$ tpfc are potent catalysts for oxygen and carbene transfer to olefins and alkanes, ${ }^{11}$ followed by full characterization of $\mathrm{H}_{3} \mathrm{tpfc}^{12}$ and its $\mathrm{Cr}^{\mathrm{V}} \mathrm{O}$, $\mathrm{Fe}^{\mathrm{IV}} \mathrm{Cl}$ and $\mathrm{Rh}^{\mathrm{III}}\left(\mathrm{PPh}_{3}\right)$ complexes. ${ }^{13,14}$ The manganese corrole [(tpfc) $\mathrm{Mn}$ ] was also found to be an epoxidation catalyst, as well as an excellent precursor to a relatively stable oxomanganese(v) corrole. ${ }^{1 b, 15}$ The apparent importance of this result together with the rather limited information on the electronic structures of manganese corroles 16,17 were the driving forces for the current investigations. A combination of HF-EPR spectroscopy, $\mathrm{X}$-ray crystallography, and magnetic susceptibility measurements, led to the conclusion that $\left[(\mathrm{tpfc}) \mathrm{Mn}\left(\mathrm{OPPh}_{3}\right)\right]$ is an authentic manganese(III) complex that does not experience significant intermolecular interactions.

Obtaining X-ray quality crystals of [(tpfc)Mn] was a difficult task; NMR examination of material from different crystallization batches revealed significant variations in chemical shifts. Since we suspected that these differences were due to solvent coordination, we added external ligands to the recrystallization mixtures. These attempts finally met with success: with triphenylphosphine oxide as additive, X-ray quality crystals of $\left[(\mathrm{tpfc}) \mathrm{Mn}\left(\mathrm{OPPh}_{3}\right)\right]$ were isolated. ${ }^{18}$ The structure of $\left[(\mathrm{tpfc}) \mathrm{Mn}\left(\mathrm{OPPh}_{3}\right)\right]$ (Fig. 1) is quite different from that of the previously reported square planar manganese(III) corrole, [(e$7,13-\mathrm{mc}) \mathrm{Mn}] .{ }^{1 b, 16}$ In the latter complex the metal is located almost perfectly within the $\mathrm{N}_{4}$ plane and the macrocycle is planar, whereas in $\left[(\mathrm{tpfc}) \mathrm{Mn}\left(\mathrm{OPPh}_{3}\right)\right]$ the manganese is $0.29 \AA$ out of both the $\mathrm{N}_{4}$ and the corrole core planes. This causes some

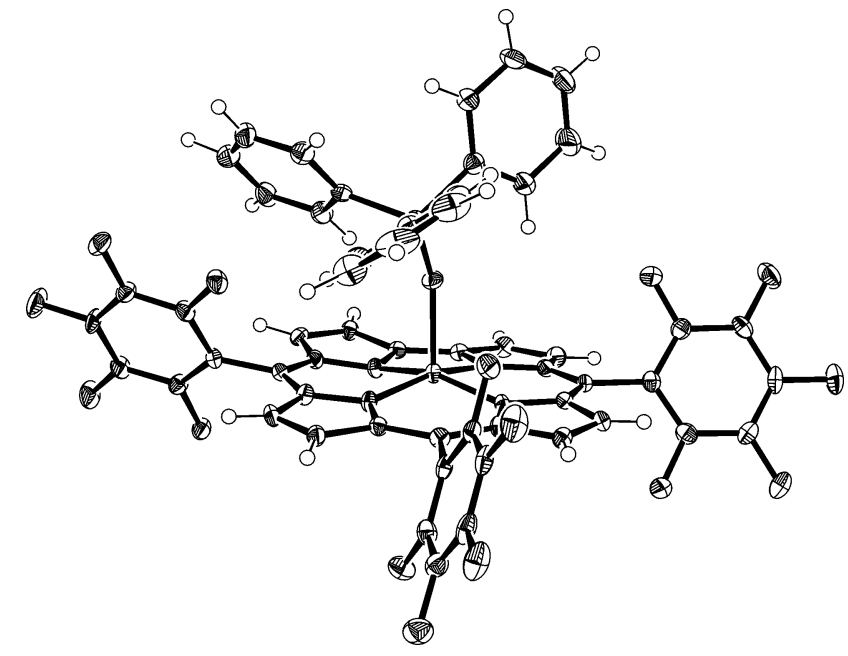

Fig. 1 ORTEP view of $\left[(\mathrm{tpfc}) \mathrm{Mn}\left(\mathrm{OPPh}_{3}\right)\right]$.

elongation of the average $\mathrm{Mn}-\mathrm{N}_{\text {pyrrole }}$ bonds $\{$ from 1.894 in [(e$7,13-\mathrm{mc}) \mathrm{Mn}]$ to $1.916 \AA$ in $\left.\left[(\mathrm{tpfc}) \mathrm{Mn}\left(\mathrm{OPPh}_{3}\right)\right]\right\}$ with slight deviations of the tpfc atoms from the mean plane. Another significant difference is the absence of interactions between the corroles in $\left[(\mathrm{tpfc}) \mathrm{Mn}\left(\mathrm{OPPh}_{3}\right)\right]$, which is a dominant factor in the structure of [(e-7,13-mc)Mn]. Rather, the potential empty space is occupied by the triphenylphosphine oxide ligand (Fig. 2).

The absence of intermolecular interactions is also reflected in the magnetic susceptibility measurements on $\left[(\mathrm{tpfc}) \mathrm{Mn}\left(\mathrm{OPPh}_{3}\right)\right]$, performed in the temperature range 2-300 K. ${ }^{19}$ The magnetic moment of $4.88 \mu_{\mathrm{B}}$ confirms that the complex possesses a simple high-spin $(S=2)$ ground state; and the very flat plateau in the $\mu_{\text {eff }} v s$. temperature plot down to 10 $\mathrm{K}$ (Fig. 3) is perfectly in line with the molecular packing deduced from the X-ray structure (Fig. 2).

Since the consequences of lowered symmetry on the electronic structures of corrole $v s$. porphyrin complexes have

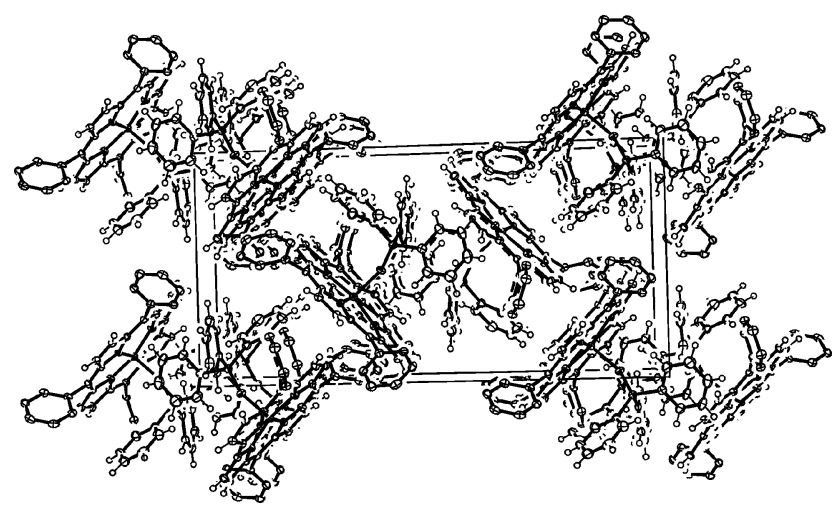

Fig. 2 Unit cell of $\left[(\mathrm{tpfc}) \mathrm{Mn}\left(\mathrm{OPPh}_{3}\right)\right]$, approximately along the $a$-axis Fluorine atoms have been omitted for clarity. 


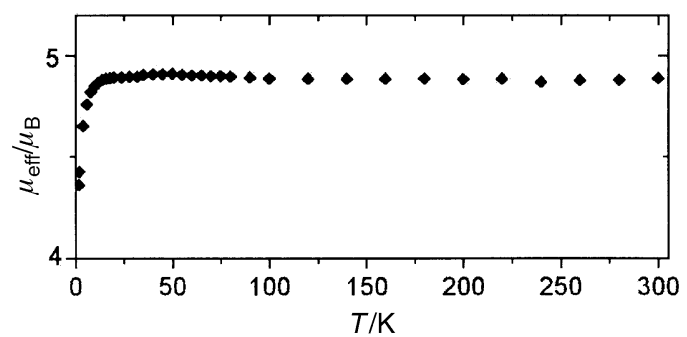

Fig. 3 Variation of the magnetic moment of $\left[(\mathrm{tpfc}) \mathrm{Mn}\left(\mathrm{OPPh}_{3}\right)\right]$ with temperature.

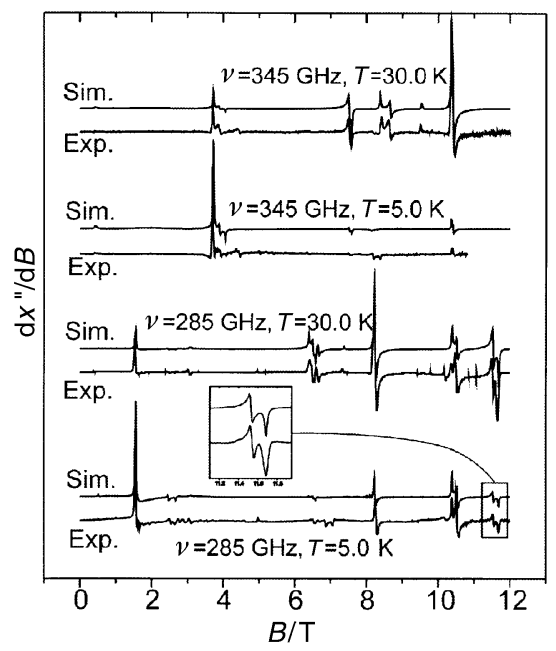

Fig. 4 Experimental and simulated HF-EPR spectra of $\left[(\mathrm{tpfc}) \mathrm{Mn}\left(\mathrm{OPPh}_{3}\right)\right]$.

not yet been quantified experimentally, we measured HF-EPR spectra of $\left[(\mathrm{tpfc}) \mathrm{Mn}\left(\mathrm{OPPh}_{3}\right)\right]$ at two different frequencies $(285$ and $345 \mathrm{GHz}$ ) and at two different temperatures (5 and $30 \mathrm{~K}$ ). The spectra shown in Fig. 4 are very well reproduced by simulations of randomly oriented powder samples employing the following parameters: $g_{\|}=1.980(4), g_{\perp}=1.994(4), D=$ $2.69(2) \mathrm{cm}^{-1}, E=0.030(3) \mathrm{cm}^{-1}, W_{1 / 2}=150 \mathrm{G}(T=5 \mathrm{~K})$, $W_{1 / 2}=180 \mathrm{G}(T=30 \mathrm{~K}){ }^{20}$ One of the most sensitive lines to $g$ value rhombicity is that centered at $8 \mathrm{~T}(285 \mathrm{GHz})$, which consists of the transitions $(|-1>\rightarrow| 0>)$ and $(|0>\rightarrow|+1>)$. The fact that this line is not split puts an upper limit of 0.005 on the difference between $g_{x}$ and $g_{y}$. An expansion of one of the easily observed line splittings attributable to the rhombic zero-field splitting is shown in the insert of Fig. 4. The rhombic zero-field splitting is small compared to that found in tris( $\beta$-diketonate) complexes of manganese(III) $\left(E=0.26 \mathrm{~cm}^{-1}, E / D=-0.06\right),{ }^{9 b}$ but we emphasize that the corresponding line is not split in the spectra of manganese(III) porphyrins and phthalocyanines. Although the lower molecular symmetry of metallocorroles compared to metalloporphyrins is also pronounced for systems with no preferred coordination geometry, ${ }^{21}$ the electronic deviation from axiality is quite small. We thus conclude that treating a corrolate as a trianionic porphyrinate is not unreasonable.

We have fully characterized a manganese complex of $\mathrm{H}_{3}$ tpfc. Employing three different methods, we have shown that $\left[(\mathrm{tpfc}) \mathrm{Mn}\left(\mathrm{OPPh}_{3}\right)\right]$ contains an authentic, isolated $S=2$ manganese(III) center.
We thank Dr M. W. Day (Beckman Institute) for assistance with the crystal structure determination and Ms S. Mossin (University of Copenhagen) and Dr A.-L. Barra (CNRS, Grenoble) for recording the HF-EPR spectra. This research was supported by the Fund for the Promotion of Research at the Technion (Z. G.), the National Science Foundation (H. B. G.), and grant \# 9800549 from the Danish Natural Science Research Council (J. B.).

\section{Notes and references}

1 (a) A major part of this work was first presented as Poster 23 in Contemp. Inorg. Chem.- II, March 12-15, 2000, College Station, Texas, and as Paper 293 in the 219th national ACS meeting in San Francisco, March 26-30, 2000; (b) abbreviations: tpfc and e-7,13-mc; the trianions of 5,10,15-tris(pentafluorophenyl)corrole and 2,3,8,12,17,18-hexaethyl-7,13-dimethylcorrole, respectively.

2 (a) B. Meunier, in Metalloporphyrin Catalyzed Oxidations, ed. F. Montanari and L. Casella, Kluwer Academic Publishers, Dordrecht, 1994, pp. 1-48; (b) J. T. Groves, in Cytochrome P450: Structure, Mechanism, and Biochemistry, ed. P. R. Ortiz de Montellano, Plenum Press, New York, 2nd edn., 1995, pp. 1-48.

3 L. Kaustov, M. E. Tal, A. I. Shames and Z. Gross, Inorg. Chem., 1997, 36, 3503 .

4 H. Volz and W. Muller, Chem. Ber., 1997, 130, 1099, and references therein.

5 N. Jin and J. T. Groves, J. Am. Chem. Soc., 1999, 121, 2923.

6 J. T. Groves and T. Takahashi, J. Am. Chem. Soc., 1983, 105, 2073.

7 Z. Gross, A. Mahammed and C. M. Barzilay, Chem. Commun., 1998, 1505.

8 P. Turner and M. J. Gunter, Inorg. Chem., 1994, 33, 1406.

9 (a) D. P. Goldberg, J. Telser, J. Krzystek, A. G. Montalban, L.-C. Brunel, A. G. M. Barrett and B. M. Hoffman, J. Am. Chem. Soc., 1997, 119, 8722; (b) A.-L. Barra, D. Gatteschi, R. Sessoli, G. L. Abbati, A. Cornia and A. C. Fabretti, Angew. Chem., Int. Ed. Engl., 1997, 36, 2329; (c) J. Krzystek, J. Telser, L. A. Pardi, D. P. Goldberg, B. M. Hoffman and L.-C. Brunel, Inorg. Chem., 1999, 38, 6121.

10 (a) Z. Gross, N. Galili and I. Saltsman, Angew. Chem., Int. Ed., 1999, 38, 1427; (b) $\mathrm{H}_{3}$ (tpfc) is commercially available (Strem Chemicals Inc.).

11 Z. Gross, L. Simkhovich and N. Galili, Chem. Commun., 1999, 599.

12 Z. Gross, N. Galili, L. Simkhovich, I. Saltsman, M. Botoshansky, D. Bläser, R. Boese and I. Goldberg, Org. Lett., 1999, 1, 599.

13 A. E. Meier-Callahan, H. B. Gray and Z. Gross, Inorg. Chem., 2000, 39, 3605 .

14 L. Simkhovich, N. Galili, I. Saltsman, I. Goldberg and Z. Gross, Inorg. Chem., 2000, 39, 2704.

15 Z. Gross, G. Golubkov and L. Simkhovich, Angew. Chem., Int. Ed., 2000, 39, in press.

16 S. Licoccia, E. Morgante, R. Paolesse, F. Polizio, M. O. Senge, E. Tondello and T. Boschi, Inorg. Chem., 1997, 36, 1564.

17 C. Erben, S. Will and K. M. Kadish, in The Porphyrin Handbook, ed. K. M. Kadish, K. M. Smith and R. Guilard, Academic Press, 2000, vol. 2, p. 233.

18 Crystal data: (tpfc) $\mathrm{Mn}\left(\mathrm{OPPh}_{3}\right), \mathrm{C}_{55} \mathrm{H}_{23} \mathrm{~F}_{15} \mathrm{MnN}_{4} \mathrm{OP}: M=1126.68$, monoclinic, space group $P 2_{1} / n, a=13.883(2), b=12.802(1), c=$ 25.952(3) $\AA$, $\beta=100.31(1)^{\circ}, V=4537.9(9) \AA^{3}, Z=4, T=98 \mathrm{~K}, D_{\mathrm{c}}$ $=1.649 \mathrm{~g} \mathrm{~cm}^{-3}, \mu(\mathrm{Mo}-\mathrm{K} \alpha)=0.44 \mathrm{~mm}^{-1}, 10384$ unique reflections, $R 1=0.044$ for 5262 observations with $F_{\mathrm{o}}>4 \sigma\left(F_{\mathrm{o}}\right), R 1=0.117(w R$

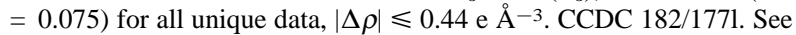
http://www.rsc.org/suppdata/cc/b0/b006299p/ for crystallographic files in .cif format.

19 The measurement was done on a pressed powder sample in a static field of $100 \mathrm{G}$ on a Quantum Design MPMS SQUID magnetometer.

20 Simulations were done by use of the full-matrix-diagonalization program SIM vers. 13.12.99, by H. Weihe, Univ. of Copenhagen. See also: J. Glerup and H. Weihe, Acta Chem. Scand., 1991, 45, 444.

21 L. Simkhovich, I. Goldberg and Z. Gross, J. Inorg. Biochem., 2000, 80, 235; J. Bendix, I. J. Dmochowski, H. B. Gray, A. Mahammed, L. Simkhovich and Z. Gross, Angew. Chem. Int. Ed., 2000, 39, in press. 